\title{
AUTONOMOUS TRAINS IN FREIGHT TRANSPORT: SHOULD THE RAILWAY NOT HAVE THE ADVANTAGE OVER THE TRUCKS?
}

\author{
STEPHAN MÜLLER \\ German Aerospace Center (DLR), Institute of Transport Research, Germany
}

\begin{abstract}
Should the automation of trains not be easier than the automation of trucks? This paper analyses the structural barriers to innovation of "autonomous freight trains" for large-scale deployment. Four theoretical effects are analysed that characterize the mechanism for innovation activities in advanced markets: (1) the hierarchical and nested architecture of value networks; (2) path dependency in technological paradigms; (3) organizational dynamics; and (4) the stalemate in technology. These four effects culminate, and the higher the maturity level of the four effects is, the more they limit innovation activities. The analysis shows that the economic mechanism strongly limits innovation activity for rail freight transport in general and also in relation to autonomous train operation. For road freight transport, the degree of maturity is less given and thus the truck is at an advantage, although the complexity of train automation in general is less than that of truck automation. The results contribute to the challenge of train automation and are worth considering in a strategic innovation policy for rail.
\end{abstract}

Keywords: autonomous trains, automated vehicles, rail freight services, innovation in freight transport, RioTinto, AutoHaul.

\section{INTRODUCTION}

Efficient freight transport is essential for economic interaction and economic development. Efficiency is assessed by its users and determined by transport system's characteristics such as its costs, service quality, accessibility, transport times and other variables. Trucking is currently most efficient for its users considering that a large part of freight is transported on road. Just in time production, complex production and value adding chains, decreasing shipment sizes, third party logistics are part of the economic paradigm enabled by trucks [1]. Moreover, to the dominance of trucks in transport chains contributed the fact that environmental costs and other external costs are not internalized in transport prices [2].

However, deep structural trends culminate in a request of the established road freight transport. Bormann et al. [3] summarize four trends: (1) digitization; (2) environmental sustainability; (3) urbanization; and (4) individualization. It needs adaption in road freight transport to address these challenges. Hence, electrification and automated driving are prominent innovation streams that address those challenges. The electrification (by e.g. battery electric drives, hydrogen or catenary hybrid truck) is tackling the environmental costs of trucking [4]. Regarding automated driving it is expected that this technology will decrease energy consumption, mainly by platoon driving modes. Moreover, anticipated impacts are an increase of road's capacity, a decrease of transport cost and an enhanced reliability [5], [6]. Additionally, mobility-as-a-service (MaaS) solutions in freight transport by, for example, new level of connectivity, sophisticated platform models for freight allocation or ride sharing enter the market and promise to increase the efficiency of road transport (e.g. the utilization of loading capacity and less empty trips). Based on the current industrial and political efforts, a likely future pathway for road freight transport is that electrified trucks will drive automated in an economic setting of MaaS. However, if the scenario of electrified, automated MaaStrucking becomes reality the railway's traditional performance parameter will be less 
competitive. Trucking would be cheaper, faster and more flexible than today and, approaches environmental friendliness and mass capability of trains. It is not improbable that a shift from rail to road will be an effect then. However, considering the high efforts and public resources invested over the last decades to achieve a shift from road to rail, the innovation stream for trucking seems to be thus quite challenging for railway's future.

Although electrified and automated MaaS-trucking will likely result in a shift from rail to road it is a contestable policy option to deprive or hinder the technology for trucking due to protect rail services. The improvements for the trucking system result from socio-political and economic pressure and are thus needed to be addressed. Without such innovation pathway the future of trucking is endangered and this, maybe most important, is challenges the functioning of the economy which is aligned with the performance of trucking. Instead, an option for the intermodal competition in freight transport can be innovation, such as the increase of automation in rail freight transport.

Considering this option, an intuition might be that the automation of trains should be easier than the automation of trucks. This is because, firstly, trains operate in a nearly closed environment, on tracks, centrally managed compared to individual vehicles on road, an open system with direct interaction with other road users, and many external influences (in particular in urban areas). Secondly, there is some long-lasting experience in the sector to automate trains. One is the automation of the metro train system in Lille, France by 1983 and in some other cities since then [7]. A SNCF consortium currently tests a driverless train for passenger transport in France [8]. The CargoSprinter, developed for the Deutsche Bahn by 1996 [9], was a self-propelled single wagon which could transport up to 10 TEU containers. The German Aerospace Center (DLR) has conceptualized a Next Generation Train Concept for cargo with autonomous single wagons for the last mile [10]. In Australia, the first driverless freight train is operated to transport mining products since mid-2019 [11]. Hence, trains should have clear advantages against trucks in time, costs and complexity when it comes to roll out the system wide automation (and electrification). Instead, however, there are only few current activities in practice towards automation of rail freight services compared to plenty towards electrified and automated MaaS-trucking. Some non-obvious barriers do hinder the innovativeness of railways.

Against this background, this article analyses the structural barriers to innovate in rail freight using the introduced example of autonomous freight trains.

The analysis applies theories from the so called "attacker's advantage" and "stalemate in technology" which are developed in innovation economics to describe the market mechanism for innovation activities in matured compared to emerging markets. Please note that we use autonomous trains in freight transport to explain the innovative capacity of rail using a concise example. Those readers who expect autonomous driving to be discussed in detail, as this amendment to this law and those subsequent technologies and that operating concept is necessary etc., might be disappointed at first sight. But please understand the economic mechanism as a fundamental background for innovation in the railway market. It also applies to other innovations like automatic coupling, ETCS and others. Understanding the mechanism helps the strategic decisions of the companies and the innovation policy for railways and ultimately also helps to implement autonomous driving on the railways "faster" than on the road.

In Section 2 the theories are briefly introduced and applied on autonomous trains. Section 3 discusses RioTinto's achievement in the AutoHaul project from the perspective of the theories. The article closes with recommendations for a strategic innovation policy towards autonomous trains and other innovations in rail freight transport. 


\section{THE INNOVATIVENESS DISTRESS OF RAILWAY: WHAT HINDERS AUTONOMOUS TRAINS AND OTHER INNOVATIONS?}

Most stakeholders likely agree that it needs innovation to improve the market offer and the market situation in rail freight services. Widespread arguments to understand why great innovations such as autonomous trains and automated coupling are not in application are: because innovations in railways are "system innovations" and there is a general "chickenand-egg problem". These arguments are evident in many cases however it needs a critical look on why the issues of system innovations and chicken-and-egg problems for many innovations could not have been overcome in the past century? To answer the question on the why rail cannot operationalize its advantage for autonomous trains compared to trucks we have chosen an approach of theories which are developed to explain why incumbent firms are disadvantaged faced with radical technology market entrants. In both cases the established is contested by and has to deal with a drastic change power.

Christensen and Rosenbloom [12] investigated this situation as an "attacker's advantage" which is based on three inquiries for explanation: First, hierarchical and nested architecture of value networks, secondly) path-dependency in technological paradigms and, thirdly) organizational dynamics. We add the theory of the "stalemate in technology" by Mensch [13] as the fourth which explains the relation of market matureness and the decrease innovative activity (towards a stalemate situation) because, without doubt, rail is faced a matured market situation since decades. All four theories are first presented and then transferred to the example of autonomous trains. Taken together, this should lead to a deep understanding of the innovative capacity of mature transport systems such as the railway today.

\subsection{The hierarchical and nested architecture of value networks}

Due to continued optimization efforts, the rail has become a sophisticated and matured product system over the course of its life time. In this section, it should be made clear that this degree of maturity can be a barrier for major innovation steps such as autonomous trains.

\subsubsection{Why innovation activity for matured transport systems is limited to incremental steps}

Christensen and Rosenbloom [12] introduced the notion of hierarchical and nested architecture of value networks to describe that in most cases products are assembled under use of other products and are sub modules of higher level products. For example, a locomotive and a wagon are produced by many downstream parts such as brake and engine and those are also made out of other parts. The many locomotive and wagon can only be used on infrastructure with switches and so on. And upstream it needs train control systems and switch control etc. (see Fig. 1). Railway is a complex architecture which has nested levels and hierarchical levels. Those levels are connected in value networks to create a functioning railway system.

The point is that the alignment and plurality of the nested and hierarchical elements allow only coordinated and incremental steps of change. Some parts are nearly impossible to change on rail nowadays such as the width of tracks. To change others needs a lot of coordinated re-orientation such as changing the block interval system needs up- and downstream adaptations (locomotive equipment, control system, management system, laws etc.). Even smaller innovations are framed by the architecture such as the wagon can be reinvented only within the frame of the structural gauge, permissible axle load and so on. The more advanced an architecture of a transport system became over time, the more this system 


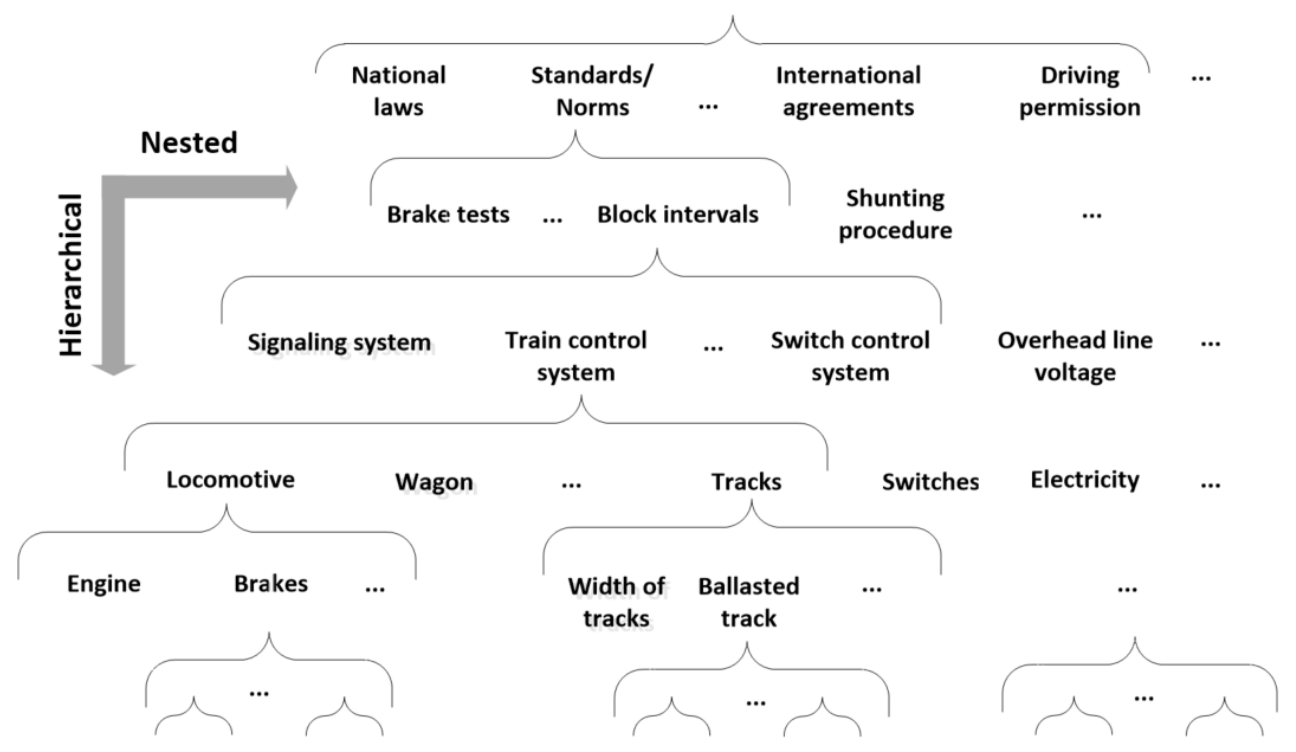

Figure 1: Example of the hierarchal and nested architecture of rail services.

is either limited to incremental innovations or it needs a system-wide, coordinated tremendously effort for the change (aligned with all interest parties what again makes incremental steps likely). Innovations are therefore blocked or in the best case enter the market as an incremental consensus solution.

2.1.2 The architecture of the value network as a barrier for autonomous trains

Looking at the architecture of the "rail freight transport" value chain, autonomous trains require adjustments at every hierarchical level and in almost every element, e.g. in infrastructure, train equipment, control systems, legislation, rotation planning. Moreover, sometimes several (competing) options for adaptations are possible. For example, train control for autonomous trains can be central with ETCS level 3 or decentral by connected sensors on trains. In the transition phase conventional trains and autonomous trains must be compatible somehow. The complexity further rises when considering that passenger and freight trains are operated on same tracks, are international and thus, adaptions or compatibility becomes a higher hierarchy issue. To achieve autonomous freight trains, almost the entire architecture has to be adapted drastically and adapted in a similar speed and intensity (horizontally and vertically aligned).

The advance of the architecture allows only small steps towards autonomous trains. To give an explicit example on this issue: The Siemens and Halske Telegraphenbauanstalt invented 1870 the relay boulder field which enables block interval train control. This innovation was a tremendously efficiency improvement for railways at that time [14]. This train control system however aligned and nested further locomotive development, train management, network management, network development, standardization, laws, rules, etc. - sustaining until today. To introduce a new train control technology like the European Train Control System (ETCS) level 2 needs enormous coordinated international efforts. Those efforts are taken by the European commission since 1996 (Directive 96/48/EC for interoperability of the trans-European high-speed rail system). Nearly 25 years later ETCS 
architecture is not deployed as the international standard. A difference between the innovations of 1870 and 1996 is that architecture has reached an enormously higher level of maturity, making the change in architecture more complex.

\subsection{The path-dependency in technological paradigms}

Almost every nation is home to a large railway company. One advantage is that this company has economic strength and robustness in a tough market environment. This section explains why incumbents however have a low innovation capacity. Especially in the case of drastic innovations like autonomous driving, there is a barrier to innovation.

\subsubsection{Why radical innovations are rejected}

With reference to a body of literature Christensen and Rosenbloom [12] argue that radical new technologies can be faithful to established companies. The notion of a radical technology is, that it is a completely new way of product architecture and functionality. Companies on market in a normal competitive mode innovate in a given technology paradigm what means that they are within an (as described before) architecture of value networks to provide a defined functionality of the product. They compete horizontal, e.g. making the best brake, or they compete by vertical integration to offer a complex product as national carriers do for example. Although radical technologies can bring about significant efficiency gains, incumbents are most likely to fight for what they have established. This strategy, however, repeatedly leads to its failure [15], [16]. The main reasons for this are:

- Radical technologies are competence-destroying: Once the architecture is created, each institution in the value network creates competences such as on technical issue, anticipation of customer needs or the development of a grounded business concept. This can be related to ownership of patents, protection such as by norms and standards, working skills within a company, production lines organization and so on. A radical technology is challenging many of those competences and devaluates them. For example, the innovation of the car devaluated massively the competence needed for horse carriages.

- The shift from product to process innovations: In a normal mode of innovation activity companies do first innovate on product level to enhance the architecture's functionality, reliability and convenience. However, they shift from product to process innovation what stabilizes or fixes the architecture from then on. The reason for the shift is that process innovations, e.g. higher efficient production, create margins when product innovations become difficult. The difficulty increases, for example, by the framing value network, technically high end, physical or economical limits (over-engineering). In a sense, the more advanced the architecture is, the more process innovations are lucrative compared to product innovations - which leads to the stabilization of the established.

- The strategic niche of radical innovations: Mass market products have high performance to satisfy the mass market demand. Radical technology normally underperforms in this market. They need market niches, where they provide new functionalities to users which are unsatisfied by mass market products. The niche is however of tremendous strategic relevance: the niche exists because the architecture of the mass market product cannot (technically, economically) satisfy this demand. When a radical technology focusses on this niche, the performance is specialized and unrivalled. Incumbents cannot or very hard serve this demand - they did not until the rise of the radical technology. Hence, the 
underperformance of the challenger compared to products in the mass market becomes largely irrelevant. The performance in a strategic niche however is the key for growth and future market dominance. For example, first cars had the power of only 1 or $2 \mathrm{hp}$ compared to more than $100 \mathrm{hp}$ of a locomotive in 1890 . This was however not relevant in the strategic niche where cars were deployed.

The point is, established companies in a technological paradigm have a) very low economic incentives and b) a strategic disadvantage to re-align the architecture of the value network from mass market products to niche market products (although some few companies can leap).

\subsubsection{The path-dependency against autonomous trains}

Path dependency implies that the actors manifest, defend and intensify their role in the architecture instead of pursuing alternatives. This has been the case with the railways for almost 200 years now.

Autonomous trains will destroy competences in the architecture. Concerned are for example, railway infrastructure companies. They made great investments in the past to enable non-autonomous trains with interlocking boxes, signaling and so on. Those elements provide a return on investment now but would become irrelevant in a world of autonomously communicating trains and operating companies. Many working skills are changing from today's planning and controlling to IT-based algorithmic, programming, computing, and hardware. Many of labor forces become obsolete which will be an issue of organizational change and labor unions. All those in the architecture, who are potential losers of the architectural re-orientation are potential brakeman of autonomous trains.

Rail freight service market is a very price sensitive market. The reason for the price sensitivity of the customs is because the competing services are considered to be very similar (homogenous products in functionality, reliability and convenience). Hence, the price becomes the selling point. However, in a price driven market margins are difficult (long term they are zero). If any actor would see the chance to compete by product innovations they would because this is the opportunity to leave the price competitive environment. However, they are captured in the architecture and margins are only possible with process innovations to higher efficiency in production. Although autonomous trains would be an efficiency increase by, for example, saving the driver costs, their rejection is likely.

In most countries normally one company dominates the national rail market. Competition increased since the market liberalization but is still on a low level. Private rail companies make their business, we can say, in niche markets which are opened by the market offer of the incumbent (often a former state owned national carrier). In a very price sensitive market, as the rail market is, those niches are not functional but private companies can operate them with a better price than the incumbent, for example, because of lower overhead costs. Maybe in many of those niches, autonomous trains could have a first application because it could decrease the production costs tremendously. However, the investments needed are very high and would decrease the margins for long time while at the same time the willingness to pay by the customs will likely decrease as well for the service with autonomous trains. The point is, it generally lacks in a functional niche for autonomous trains, where the investment is promising. Just to replace the production system for the same product will not ensure returns on investment. However, this lack is not a natural law but the path-dependency of the established players narrows them not to search for functional niches of new products. 


\subsection{Organizational dynamics}

If an innovation is beneficial, it seems to make economic sense to introduce it to the market. In this section we will explain why an innovation that appears to increase efficiency to such an extent as autonomous trains still does not enter the market or will enter it only with a considerable delay.

\subsubsection{Why breaking out of the architecture is difficult although willingness}

Each company has a culture, technical and economic structure and develops knowledge and competences in its market over time. Christensen and Rosenbloom [12] explain that companies however tend to focus on their core business and core competences. Hence, they narrow the thinking and decisions for future innovations on their established value network and lose their capability to develop or think in alternative architecture. The decentral decisions in a company are guided by the same mind and are thus i) pre-determined and ii) aligned. "We've always done it this way". It becomes a collectively chosen pathway even if decentral in many aspects (economic structure, technical structure, cultural structure, even the sectoral structure).

The point is, on company level and on sectoral level stabilizing forces align structures and decisions. Thus, the willingness to break out of the architecture, which may emanate from one or the other decision-maker at any level of the architecture, is subordinated to organizational dynamics and its framing culture.

\subsubsection{The slowing organizational dynamics against autonomous trains}

Autonomous trains would have some advantages such as cost and reliability. Shifting train operations to autonomous trains should be a beneficial economic decision. However, high end automation of trains means a disruption of the existing railway system. From the perspective of the incumbents this means to open or rather to destabilize the established structures. No one knows whether incumbents will be the winners of this disruption or it might be a new entrant. Furthermore, it is clear that a suited and transferrable concept of autonomous trains has to be designed in a first stage. To find the concept which fits to market demand is costly and risky, likely linked to mis-investment and failure. It needs decades to find a general operated "design" and the more advanced the process is, the more the former established patents, processes, routines etc. are devaluated. The crux however is, that all these has to be done in market niches - there will not be an initial roll out of the new technology on national or international scale but to define the design to specific demand needs, for example, a company in rural condition. No one knows the transferability of a tested design in the niche to other customs towards a mass market.

National rail carriers for example are hence stabilized in this manner by many interest parties (politically, technically, economically) which makes it difficult to change the organizational dynamic towards autonomous trains.

\subsection{The stalemate in technology}

The railway market has been liberalized in most countries. As a result, established and new companies are competing for customers on the market. Surely it should be expected that innovations in a liberalized market environment will be used to make products better. This section explains the economic mechanism why innovations in a liberalized railway market are not a matter of course. 


\subsubsection{Why the market mechanism can block innovations}

Normally, capital is invested if a return can be expected with a manageable risk. This also applies to investments in innovations. However, the market situation makes a difference on the return that can be expected. To explain the mechanism we will consider two extreme examples: When a radical technology enters the market, it is a "young technology". Major improvements in this technology can be achieved with relatively little capital input because the technology and their market are almost unexplored. Furthermore, significant innovation steps trigger purchases at high prices and thus market growth. The return on investment is correspondingly high and the risk low. Rapidly growing markets are therefore very attractive for investment in innovation. On the contrary, in a saturated market the technology is optimized and further innovations are very expensive but not significant. The lack of innovation does not trigger market growth. In the extreme, if the products are not innovative at all, the incentive to buy a new product is limited to replacement purchases. Thus, the investment in innovations is not attractive because such an investment is high, is risky and is, if given, little profitable. Therefore, growing markets or the expectation of market growth can be postulated as a prerequisite for investment in innovation. This unveils the mechanisms: no (expected) market growth means no innovation activity and, no innovation activity means no market growth. Mensch [13] described a situation as the stalemate in technology when a market is unable to innovate and to grow anymore - the market dynamic is paralyzed.

The point of the market mechanism is the nature of increasing market's matureness implies a stalemate in technology and the stalemate in technology is a strong barrier for innovation activity. Normally this market either is degenerating by market forces or subject to be disrupted from external technologies or is stabilized by subsidies.

\subsubsection{The stalemate in technology of freight railways}

In the Rail Freight Masterplan in Germany, the stakeholders postulated for the sectoral basic situation: "[...] in Germany, the largest rail freight market in Europe, only a few railway undertakings are recording appreciable growth and income that is just about in the black. However, these low rates of return are not sufficient for funding the investment required to safeguard the future of rail freight on a sustained basis" [17]. This statement indicates the technological stalemate. No market growth means no incentive (ability) to invest in innovations and in turn, no investment in innovations implies no market growth. Realistically, rail freight services have a production system which is not that much advanced compared to hundred years ago: centrally organized management, fixed slots, train composition with handmade coupling, frequent wagon checks, shunting and brake tests etc. Even the age of the rolling stock is aged, for example in Europe with an average about 30 years [18]. Although innovation to modernize rail freight are available such as automated coupling, dynamic pivoted bogies and the 5L wagon (low noise, lightweight, long-running, logistics capable, LCC-oriented) [19], [20], they are however not in operation - an important argument why they are not is the technological stalemate in the market which exists since decade already. Autonomous trains, which are a much larger technological and organizational transition, have thus very challenging market conditions as well. The market mechanism is a strong barrier to this innovation. It is difficult for market participants to provide it from their own economic power - it is probably necessary to subsidize innovation impulses.

\subsection{Summary of the challenge}

Four effects are discussed that are barriers for autonomous trains in large scale deployment: 
1. The architecture of value networks: The hierarchical and nested architecture of the valueadded network for rail freight transport, which has been developed for almost 200 years, only allows minor, aligned innovation steps. However, the innovation of autonomous rail freight transport means a massive change in the architecture; indeed, it means its disruption. To achieve this would mean a very long lasting coordinated undertaking.

2. The path-dependency: Some very important players would lose market power, profits and competences by autonomously operating trains. The potential losers of the technology are its potential brakeman.

3. Organisational dynamics: The incentive to develop autonomously running trains for an uncertain niche market, as expensive as the investment for the technology is, is not attractive. It makes economic sense to focus on the mass market.

4. The stalemate in technology: the market is not growing because there is a lack of innovation, and the lack of innovation is because the market is not growing. It is the inability of the market players to initiate positive market dynamics in this market environment. In the case of rail freight services this steady state exists since decades.

Although automation in rail freight might be strongly efficiency enhancing, might create new market growth from niches, profitability and social benefits, the four effects reflect why automation is not a common trend in the rail freight sector: The mechanism of innovation economics implies a deep innovativeness distress for rail freight.

In principle, the mechanism of innovation economics is relevant for the automation in road freight transport too. Briefly, the major difference from rail to road transport is, that road freight transport is not that much advanced as rail freight is. For example, the architecture is not that much matured in alignment and hierarchy even if they are aligned and nested but on a lower level. Another issue is that their market is not in the stalemate in technology - road freight logistics is a growing and (still) profitable business what triggers innovations activity.

Summing up, the state of rail freight do not support or only allows with considerable delay that autonomous trains become a sector-wide (cross-national) innovation stream.

\section{THE DIFFERENCE OF THE AUTOHAUL PROJECT TO THE MAJORITY OF RAILWAY APPLICATIONS}

The autonomous train in the AutoHaul project is without doubt a great achievement, from technical point of view as well as all the organizational aspects needed to implement the technology. This projects might contradict the discussion made before on the, let us say, innovativeness distress in railways. However, there are some important differences to the majority in the rail sector. Those can be pointed out as (based on [11]):

- The growing market: The Australian-British mining company RioTinto applied an autonomous train in a market where a) the mass capability is the functional core, b) where a long term growth is expected. Although the initially calculated costs of the project have been extravagated by far and needed nearly one billion in total - in long term growing condition the return on investment can be expected for the investor.

- The closed architecture: The mining company operated human driven rail services to transport the mining products close to an general architecture of railway which can be found everywhere in the world. However, they are exclusive users of the infrastructure and could re-create a disruptive architecture by a single company's decision. The point is not all to devaluate the achievement but to point out, that normally many (hierarchical and nested) companies have to align to such a development step. 
- It was a mining company, not a rail company: What stereotypical for disruption is, is that it is rarely introduced by incumbents. Also in the case of the AutoHaul project, it was not a railway company which introduced the autonomous train but a mining company. Rail transport is "only" a part to fulfill the function of the product of RioTinto: mining. The company its organizational dynamic was not narrowed or rather pathdependent of the established rail system when rail is not the core product.

- The specific framework conditions: It is not the point to say that it seems to be obviously easier to run driverless trains in the Australian outback than in, let us say, densely populated central Europe. Solutions can be found to any circumstances. The point is, that it needed collaboration between public authorities and the project team to realize driverless trains. Many of existing rules, norms and standards needed to be overthought and permitted for this achievement. It needed politicians, officials and administrators that where open to leave the safety zone of the established framework for rail operations. In the Australian case there was this supportive attitude and this was one of the decisive factors for the success of the project - they overcame the path-dependency and the established organizational dynamics.

Considering the AutoHaul project on a closer look we see that the theoretical aspects where overcome. However we also see, that AutoHaul is distinct to the general rail freight service sector. In the next section we address the learnings into policy implications.

\section{POLICY IMPLICATIONS}

Without doubt, innovation is the key to trigger competitiveness of railways against trucking, new market growth and a shift from road to rail. To bring autonomous trains into practice is possible as the mining company RioTinto has demonstrated with the AutoHaul project. However, it needs to address the issues of the innovativeness distress of railways in the policy strategy to achieve it in the rail freight market. From the theories applied, for strategic innovation policy in rail freight following cornerstones can be provided:

- $\quad$ The state is often needed as a donor: In the situation of the technological stalemate, market players are generally not able to invest in innovations. This means that public funds or correspondingly state-subsidized loans are indispensable to trigger innovation in the rail freight services.

- Accepting the "impending" radical change-shaping a new role for rail freight services: a reversal trend for the market situation cannot be achieved with the incremental improvement of the market supply. It needs radical new technologies and business concepts to shape a new role of rail freight services in transport markets and, in new transport markets.

- Growth from relevant market niches: Instead of designing and envision a possible future system on the drawing board, it is needed to test the market demand for new products in small areas of application. It needs strategic niches were a new architecture of rail provides new functionality and thus willingness to pay. This applies both to the geographic scope and to the demand group. If the concept is successful in the market niche and transferable for further demand groups, the market supply will gradually grow in line with the market needs.

- Involvement of new actors: Established market players can incorporate radical innovations into their production processes. To this end, there must be a willingness to grow out of the niche and to revise the market offering. Since new players are not captured in architecture of a value network, they naturally have a higher willingness to 
create a new one. In case the incumbent architecture is a kind of closed society, this would be a requirement. It is therefore particularly important to attribute a high potential to new players to give impetus to innovativeness in rail freight transport.

- Radical innovations need adapted framework conditions: A radical innovation, which revolutionizes the previous technological basis, is naturally not suitable for established production processes, standards, institutions, etc. They therefore need test fields, progressive thinking and acting authorities, ideal protection against resentment as well as capital/subsidies in order to gain access to established practice.

- $\quad$ Not the state selects the winner but the winner selects the support of the state: It makes no economic sense to select a new winning technology centrally (and possibly even on the basis of proposals from established market players). Many experiments and funding that is as open to technology as possible create a situation in which an effective market selection takes place and a really suitable solution, the winning technology, is created. Even if many ideas will fail, which means lost public funds in the first place, this helps to find a winning technology by learning from failed experiments. It is also more decisive to what extent society would benefit from a sustained, self-driven growth in rail freight transport.

The current flow of knowledge towards automated driving can be seen as an opportunity to break up established structures in rail freight transport and to re-launch the system's path to new market growth, profitability and social benefits. However, an innovation policy is needed that takes into account the specific characteristics of the current innovativeness distress in rail freight and the corresponding policy concepts.

\section{REFERENCES}

[1] Blanquart, C. \& Burmeister, A., Evaluating the performance of freight transport: A service approach. European Transport Research Review, 1, pp. 135-145, 2009.

[2] Union Inter Des Chemins Fer (UIC), External costs, 2015. https://uic.org/supportactivities/economics/external-costs. Accessed on: 19 Sep. 2019.

[3] Bormann, R., Fink, P., Holzapfel, H., Rammler, S., Sauter-Servaes, T., Tiemann, H., Waschke, T. \& Weirauch, B., The future of the German automotive industry: Transformation by disaster or by design? Wiso Diskurs, Friedrich Ebert Stiftung, 2018.

[4] Moultak, M., Lutsey, N. \& Hall, D., Transitioning to zero-emission heavy-duty freight vehicles. White Paper, Washington, DC, 2017.

[5] Kunze, R., Haberstroh, M., Ramakers, R., Henning, K. \& Jeschke, S., Automated truck platoons on motorways: A contribution to the safety on roads. Automation, Communication and Cybernetics in Science and Engineering 2009/2010, eds S. Jeschke, I. Isenhardt \& K. Henning, Springer: Berlin and Heidelberg, 2011.

[6] Müller, S. \& Voigtländer, F., Automated trucks in road freight logistics: The user perspective. Advances in Production, Logistics and Traffic, eds U. Clausen, S. Langkau \& C. Thaller, Springer, 2019.

[7] Wang, Y., Zhang, M., Ma, J. \& Zhou, X., Survey on driverless train operation for urban rail transit systems. Urban Rail Transit, 2, 106-113, 2016.

DOI: $10.1007 / \mathrm{s} 40864-016-0047-8$.

[8] Zasiadko, M., SNCF tests its first autonomous trains, 2019. www.railtech.com.

[9] Forschungsinformationssystem (FIS), CargoSprinter, 2019.

www.forschungsinformationssystem.de/servlet/is/402123/ Accessed on: 26 Feb. 2019. 
[10] German Aerospace Center (DLR), NGT cargo: What freight trains of the future will look like, 2017. www.dlr.de/dlr/en/desktopdefault.aspx/tabid-10280/385_read-21934/ year-all/\#/gallery/26733. Accessed on: 19 Sep. 2019.

[11] RioTino, Successful rollout of AutoHaul ${ }^{\mathrm{TM}}$ positions WA as global rail technology leader, 2019. www.riotinto.com/en/news/releases/AutoHaul-successfully-deployed.

[12] Christensen, C.M. \& Rosenbloom R.S., Explaining the attacker's advantage: Technological paradigms, organizational dynamics, and the value network. Research Policy, 24, pp. 233-257, 1995.

[13] Mensch, G., Das technologische Patt: Innovationen überwinden die Depression. Umschau Verlag Breidenstein KG, 1975.

[14] Kirchberg, P., Die Entwicklung des Eisenbahnnetzes in Deutschland von der Reichsgründung bis zur Gegenwart, 1993. DOI: 10.11588/ih.1993.0.22599.

[15] Porter, M.E., The competitive advantage of nations. Harvard Business Review, March-April, 1990.

[16] Christensen, C.M., The Innovator's Dilemma: When New Technologies Cause Great Firms to Fail, Harvard Business School Press: Boston, MA, 1997.

[17] Federal Ministry of Transport and Digital Infrastructure (BMVI), Rail freight masterplan, 2017.

www.bmvi.de/SharedDocs/EN/publications/rail-freight-masterplan.html.

[18] Scordamaglia, D. \& Katsarova, I., The fourth railway package: Another step towards a single European railway area. European Parliamentary Research Service, PE 579.088, March 2016

[19] König, R. \& Hecht, M., White paper innovative rail freight wagon 2030: The "5L" future innovative initiative as a basis for growth in rail freight transportation, 2012.

[20] Thunder, T. \& Islam, D., Assessment of existing and future rail freight services and technologies for low density high value goods in Europe. European Transport Research Review, 10(9), 2017. 